\title{
Does the Exercise and Self-Esteem Model Work on Wheelchair Basketball Players?
}

\author{
Samir H. Qasim', Yaser Telfah', Yazan Haddad' and Mohammad F. AbuMoh'd' \\ 'Yarmouk University, Faculty of Physical Education, Irbid, Jordan
}

\begin{abstract}
This study aimed to investigate exercise self-efficacy, physical self-worth, and global self-esteem levels of athletes with physical disabilities. To examine the exercise and self-esteem model on athletes with disabilities, we explored the hierarchical relationship between self-efficacy, physical self-worth, and global self-esteem. Forty-one $(\mathrm{N}=41)$ basketball players who participated in the West Asian Championship answered the following three questionnaires: Exercise Self-Efficacy Scale, Physical Self-Description Questionnaire, and Rosenberg Self-Esteem Inventory. Descriptive statistics and the Pearson correlation coefficient were used for data analysis. Study participants achieved relatively high scores in all three variables: exercise self-efficacy

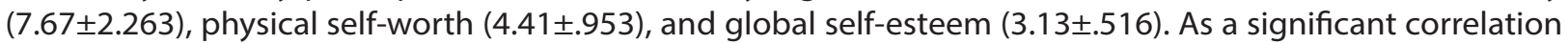
was found between exercise self-efficacy and physical self-worth but not between physical self-worth and global self-esteem, the exercise and self-esteem model concept was not supported in the present study.
\end{abstract}

Keywords: physical disability, exercise self-efficacy, physical self-worth, global self-esteem, EXSEM

\section{Introduction}

Among all the theories present in the literature that aimed to explain the models behind self-esteem improvement due to physical activity, it seems that the exercise and self-esteem model (EXSEM), developed by Sonstroem and Morgan (1989), has been the most acceptable model among researchers either in its original or adapted forms (Fox \& Wison, 2008). This model suggests that exercise engagement enhances exercise self-efficacy, which leads to better physical self-worth. As a result of the physical self-worth improvement, global self- esteem is also likely to be improved (Figure 1).

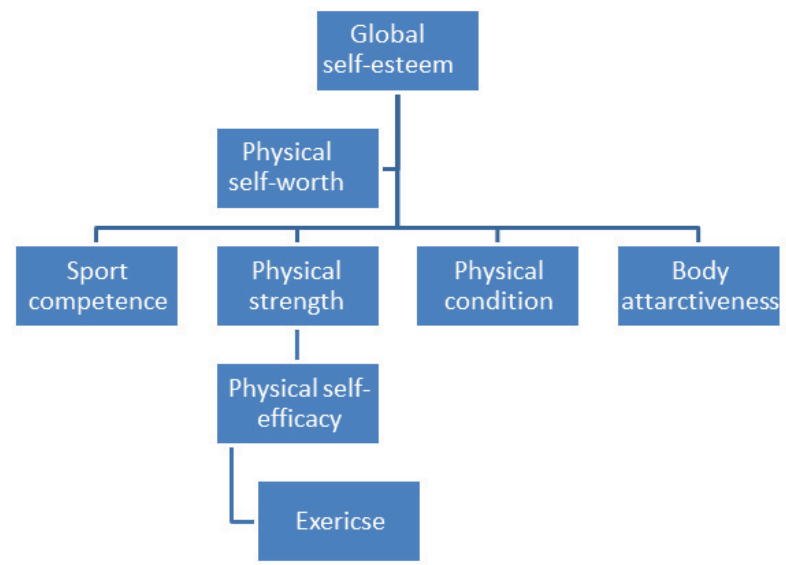

Figure 1. The EXSEM (Sonstroem, Harlow, \& Josephs, 1994)

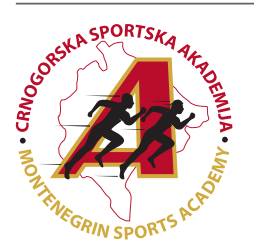

Correspondence:

S. Qasim

Yarmouk University, Faculty of Physical Education, Defense Street, Swimming Pool Building (AA3), 21163, Irbid, Jordan

E-mail: samir.qasim@yu.edu.jo 
According to the EXSEM, increased exercise self-efficacy, which is assumed to be improved by constant exercising, is a fundamental component for global self-esteem improvement. Self-efficacy has been described as a person's belief about what (s)he can do under different sets of conditions regardless of the skills (s)he possesses (Bandura, 1997); Bandura further argued that different people with similar skills could have different beliefs about their abilities, and people may perceive their abilities differently within various conditions. In addition, self-efficacy has been found to be a significant instigating force in forming intentions to exercise and in maintaining the practice for an extended time (McAuley, 1993). According to the EXSEM, a physically active person will increase his/her exercise self-efficacy. This belief in the ability to exercise for an extended period leads to better physical self-worth. Physical self-worth may be described as a multidimensional hierarchical subjective perception and affective evaluation of people's various physical traits. It describes appearance, attributes, abilities and provides a substantive interface between the individual and the outside world. Interestingly, the EXSEM focuses only on the physical self-worth, and not other self domains, which has been assumed as the best predictor of global self-esteem (Harter, 2012). Global self-esteem, however, is an overall statement of the degree to which an individual perceives himself or herself to be an "OK person", dependent on whatever criteria that individual uses to determine the meaning of "OK" (Fox, 1997).

As a model that explains self-esteem changes due to exercise, the EXSEM has been considered as a potential help for researchers to understand the relationships between exercise engagement and self-esteem (McAuley et al., 2005) and has been widely accepted in the literature. For example, Elavsky (2010) examined the EXSEM in middle-aged women $(\mathrm{N}=143)$ over a two-year period following a randomized control trial. $\mathrm{He}$ found that increased physical activity increases exercise self-efficacy, reduces body mass index (BMI), improves physical self-worth and global self-esteem. Also, Moore, Mitchell, Bibeau, and Bartholomew (2011) aimed to determine whether changes in response to resistance training of college students follow the hierarchical structure of the EXSEM. Since the results appeared to support the EXSEM, the authors strongly recommended that EXSEM be examined with different population groups.

Although more similarity than difference has been reported between athletes with disabilities and athletes without disabilities on psychological measurements (DePauw \& Gavron, 2005), limited research has focused on examining the EXSEM on people with disabilities. For instance, Qasim, Ravenscroft, and Sproule (2014) investigated the effect of karate practice on the self-esteem of young adults with visual impairment following the EXSEM. Improvement in exercise self-efficacy, physical self-worth, and global self-esteem was reported, but a correlation between these three variables was not examined. In addition, Shapiro and Martin (2010) found a positive relationship between physical self-worth and global self-esteem in athletes with physical impairments but not between physical self-worth and physical activity participation. Importantly, they reported neither exercise self-efficacy nor global self-esteem levels of their participants. This study, therefore, investigated the exercise self-efficacy, physical self-worth, and global self-esteem of athletes with physical disabilities. The second aim was to examine the hierarchical relationship between self-efficacy, physical self and global self-esteem.

\section{Methods}

\section{Participants}

After obtaining approval from the internal committee at the faculty of physical education at Yarmouk University for conducting this study, basketball coaches of four national teams that participated in the West Asian Championship were contacted. Information and consent sheets were distributed to the participants. All the players were happy to be involved in the study. Participants recruited for this study were 41 players $(\mathrm{N}=41)$ from four wheelchair basketball teams. All players were male (age $=31 \pm 6.6$ years) players for their national teams. Participants' disabilities included cerebral palsy $(\mathrm{N}=18)$, spina bifida ( $\mathrm{N}=13)$, leg length difference $(\mathrm{N}=6)$, and four (4) participants whose disability was not diagnosed.

\section{Measurements}

Exercise Self-Efficacy: The Exercise Self-Efficacy Scale (EXSE) was developed by McAuley (1993). The scale was developed for sedentary middle-aged adults and consists of eight questions in which participants have to rate their confidence to participate in moderate physical activity three times for more than 40 minutes during the next week, the next two weeks; and so forth until the eighth week. The following is an example of the first item of the EXSE: "I am able to continue to exercise three times per week at moderate intensity, for $40+$ minutes without quitting for the next week". Also, this scale captures variation in mode of activity rather than focusing solely on aerobic activity (Elavsky et al., 2005).

Furthermore, when athletes answer this questionnaire, they should take into account the challenges that are expected during a specific period. Such a form of questionnaire supports Bandura's view to self-efficacy which could be described as persons' belief in their ability to handle specific challenges that helps them to feel satisfied with their abilities (Bandura, 1977). The items on the EXSE scale were ranked on the basis of a 100-point percentage scale composed of 10-point increments, ranging from $0 \%$ (not at all confident) to $100 \%$ (highly confident). The scale has been used with people with disability as well (Motl, McAuley, \& Snook, 2007; Qasim et al., 2014). Motl et al. (2007) reported internal consistency based on coefficient alpha for the EXSE 99.

Physical Self-Worth: Physical self-description questionnaire (PSDQ) (Marsh et al., 1994) and Richards Physical SelfConcept Scale (Richards, 1988) are similar to the Physical Self-Perception Profile (PSPP) (Fox \& Corbin, 1989) and were designed for the same purposes. Concerning all measurements that have been developed for measuring physical self-worth, Sabiston, Whitehead, and Eklund (2012) reported that the PSPP and PSDQ are the best measures for physical self-perception. However, we decided to apply the PSDQ that have been widely used in the literature and has shown high internal reliability (Marsh, Asci, \& Tomas, 2002) and median test-retest correlation (Marsh, Papaioannou, \& Theodorakis, 2006). Additionally, the PSDQ has been used in the Arabic language. Furthermore, Shapiro \& Martin (2010) used the PSDQ with athletes with physical disabilities. The PSDQ is a 70-item questionnaire that measures physical self-perception across nine domains. The questionnaires were distributed and returned before the competitions began. This was done to avoid possible impact of the games results on any of the examined variables.

Global Self-Esteem: Rosenberg Self-Esteem Inventory (SEI), developed by Rosenberg (1965), was used for self-esteem 
measurement. The measure is a well-validated 10-item assessment of one's overall evaluation of self-worth. This unidimensional scale is a content-free measurement that assesses only global self-esteem and not self-esteem domains. It has been widely used in different self-esteem research fields, including physical activity (Fox, 1997). All items are answered using a four-point Likert scale format ranging from strongly agree to strongly disagree. The following is an example of the first item of the SEI: "On the whole, I am satisfied with myself".

\section{Analysis}

For descriptive statistics, we used means and standard de- viations. Pearson correlation coefficient was applied to measure correlations physical self domains (including physical self-worth) and exercise self-efficacy and global self-esteem using SPSS version 22.

\section{Results}

We found that participants from the current study had relatively high exercise self-efficacy (Mean $=7.67 \pm 2.263$ out of $10)$, physical self-worth (Mean $=4.41 \pm .953$ out of 6$)$, and global self-esteem (Mean=3.13 \pm .816 out of 4 ) (Table 1 ). In addition, it appears that global self-esteem achieved the highest mean followed by exercise self-efficacy and physical self-worth.

Table 1. Descriptive Statistics ( $N=41)$

\begin{tabular}{lccc}
\hline \multicolumn{1}{c}{ Variables } & Minimum & Maximum & Mean \pm SD \\
\hline exercise self-efficacy & 3 & 10 & $7.67 \pm 2.263$ \\
physical self-worth & 2 & 6 & $4.41 \pm .953$ \\
global self-esteem & 1 & 4 & $3.13 \pm .816$ \\
\hline
\end{tabular}

Furthermore (Table 2), exercise self-efficacy is significantly related to physical self-worth but not to global self-esteem. In addition, exercise self-efficacy was significantly (at the 0.01 level) related to most of the physical self- domains, except health, body fat, and physical appearance. No significant relationship was found between physical self-worth and global self-esteem. Only the health domain was significantly correlated to global self-esteem.

Table 2. Analysis of correlation between exercise self-efficacy, physical domains, physical self-worth and global self-esteem $(\mathrm{N}=41)$

\begin{tabular}{|c|c|c|c|}
\hline Variables & Correlation & exercise self-efficacy & global self-esteem \\
\hline \multirow{2}{*}{ Health } & Pearson Correlation & .279 & $.372(*)$ \\
\hline & Sig. (2-tailed) & .077 & .017 \\
\hline \multirow{2}{*}{ Coordination } & Pearson Correlation & $.554\left(^{* *}\right)$ & .050 \\
\hline & Sig. (2-tailed) & .000 & .758 \\
\hline \multirow{2}{*}{ Physical activity } & Pearson Correlation & $.720\left(^{* *}\right)$ & .075 \\
\hline & Sig. (2-tailed) & .000 & .642 \\
\hline \multirow{2}{*}{ Body fat } & Pearson Correlation & .118 & .140 \\
\hline & Sig. (2-tailed) & .464 & .384 \\
\hline \multirow{2}{*}{ Sports competence } & Pearson Correlation & $.634\left(^{* *}\right)$ & .164 \\
\hline & Sig. (2-tailed) & .000 & .307 \\
\hline \multirow{2}{*}{ Physical appearance } & Pearson Correlation & .259 & -.005 \\
\hline & Sig. (2-tailed) & .102 & .976 \\
\hline \multirow[t]{2}{*}{ Strength } & Pearson Correlation & $.408\left(^{* *}\right)$ & -.119 \\
\hline & Sig. (2-tailed) & .008 & .459 \\
\hline \multirow{2}{*}{ Flexibility } & Pearson Correlation & $.579\left(^{* *}\right)$ & -.036 \\
\hline & Sig. (2-tailed) & .000 & .822 \\
\hline \multirow{2}{*}{ Endurance } & Pearson Correlation & $.516\left(^{* *}\right)$ & .015 \\
\hline & Sig. (2-tailed) & .001 & .925 \\
\hline \multirow{2}{*}{ physical self-worth } & Pearson Correlation & $.552\left(^{* *}\right)$ & .075 \\
\hline & Sig. (2-tailed) & .000 & .642 \\
\hline \multirow{2}{*}{ global self-esteem } & Pearson Correlation & 0.133 & \\
\hline & Sig. (2-tailed) & 0.405 & \\
\hline
\end{tabular}

Legend: ${ }^{* *}$ Correlation is significant at the 0.01 level

\section{Discussion}

This study investigated exercise self-efficacy, physical selfworth, and global self-esteem levels of wheelchair basketball players. Results of this study show that the participants achieved relatively high scores in all three domains. While most sport psychology researchers have typically focused on performance self-efficacy (Martin, 2008), very few researchers have examined self-efficacy with wheelchair athletes (Martin, 
2002). Considering that this study was conducted on elite athletes, it is not surprising to find that exercise self-efficacy and physical self-worth were high. As this study was conducted on athletes who regularly participate in competitions it is expected to find that they feel able to continue exercising for a specified period. In addition, past success in training and competitions are essential antecedents of self-efficacy (Bandura, 1997). It appears that participants from our study achieved higher scores in physical self-worth compared to the scores of athletes from the previous study (Ferreira \& Fox, 2008). We suggest that athletes from our study were physically prepared as they were supposed to play in the regional championship which could have had impact on their physical self. This means that that they felt physically prepared for the competitions. This finding has been supported by Cocquyt and Sigmund (2011) who found a positive relationship between sport participation and increased self-perception among people with physical disabilities. Additionally, Scarpa (2011) found that adolescents and young adults with physical disabilities who regularly exercise achieved higher scores in global self-esteem and physical self-worth than their peers who did not exercise regularly. Therefore, relatively high scores of physical self-worth and global self-esteem become clearer.

Furthermore, results from the current study show that the participants had relatively high levels of global self-esteem although it has been believed that people with physical disabilities have low self-esteem due to their disability (Rumsey \& Harcourt, 2004). Global self-esteem of young athletes with physical disabilities was found in a previous study (Sherrill, Hinson, Gench, Kennedy, \& Low, 1990). The overall score of global self-esteem in the current study was 3.32 out of 4 compared to 3.1 in young athletes with physical disabilities. However, in the study of Ferreira and Fox (2008), wheelchair basketball players had medium levels of global self-esteem. This disagreement in the results could be due to the regional championship that was organized during data collection for the current study. Although this study did not investigate the effect of exercise on global self-esteem, the participants' relatively high level of self-esteem may be explained by the fact that they were athletes. It has been claimed by Buckworth, Dishman, O'Connor, and Tomporowski (2013) that sport participation is related to improved self-esteem of people with disabilities.

\section{Acknowledgements}

We thank all participants and their coaches for cooperation and willing to contribute to this project.

\section{Conflict of Interest}

The authors declare that there are no conflicts of interest.

Received: 28 July 2019| Accepted: 19 November 2019| Published: 01 February 2020

\section{References}

Bandura, A. (1977). Self-efficacy: toward a unifying theory of behavioral change. Psychological Review, 84(2), 191-215.

Bandura, A. (1997). Self-efficacy: The exercise of control (1st ed.). New York: W.H. Freeman and Company.

Brown, J.D., \& Marshall, M.A. (2006). The three faces of self-esteem. In M. Kernis (Ed.), Self-esteem: Issues and answers (pp. 4-9). New York: Psychology Press.

Buckworth, J., Dishman, R., O’Connor, P., \& Tomporowski, P. (2013). Exercise Psychology (2nd ed.). Champaign, IL: Human Kinetics.

Cocquyt, M., \& Sigmund, E. (2011). The impact of competition in physical activity and sport on the self-perception of individuals with physical disabilities. Acta Gymnica, 41(1), 43-50.
The second aim of this study was to investigate a correlation among exercise self-efficacy, physical self-worth (including its subdomains) and global self-esteem. We found a significant correlation between exercise self-efficacy and most physical self-domains (including physical self-worth). A significant correlation did not appear only between exercise self-efficacy and each of health, body fat, and physical appearance. This result is concurrent with previous findings that demonstrated that physical self-worth subdomains influence exercise self-efficacy (Sonstroem et al., 1994). Moreover, significant correlations between physical self-worth subdomains and exercise self-efficacy suggest that physical activity participation leads to better perception of exercise abilities and consequently improves physical self-worth. A correlation between regular exercise habits, as EXSE measures, and increased self-efficacy has been reported (Bandura, 1997). However, no significant correlation has been found between exercise self-efficacy and global self-esteem.

A significant and unexpected result is that no significant correlation existed between global self-esteem and physical self-worth. Only one physical subdomain, health, was found to be correlated to global self-esteem. This result does not support previous findings and consequently disagrees with the EXSEM concept. It also may suggest that participants from the current study did not consider physical self-worth as an essential domain of their lives as it has been reported that only domains of high personal importance exert a substantial effect on global self-esteem while evaluations in the domains of low personal importance do not (Brown \& Marshall, 2006). This means that only those self-esteem domains that are perceived to be relevant may affect, either positively or negatively, global self-esteem while unimportant domains do not impact global self-esteem.

Although this study revealed that wheelchair basketball players have relatively high exercise self-efficacy, physical selfworth, and global self-esteem, it does not support the EXSEM. A significant correlation between exercise self-efficacy and physical self-worth was found but not between physical selfworth and global self-esteem. The present study did not investigate the importance of the physical self-domain, and therefore we recommend future research to include instruments that measure the importance of the physical self.

DePauw, K.P., \& Gavron, S.J. (2005). Disability sport (2nd ed.). Champaign, IL: Human Kinetics.

Elavsky, S. (2010). Longitudinal examination of the exercise and self-esteem model in middle-aged women. Journal of Sport and Exercise Psychology, 32(6), 862-880.

Elavsky, S., McAuley, E., Motl, R.W., Konopack, J.F., Marquez, D.X., Hu, L., Jerome, G.J.,\&Diener, E. (2005). Physical activity enhances long-term quality of life in older adults: efficacy, esteem, and affective influences. Annals of Behavioral Medicine, 30(2), 138-145.

Ferreira, J.P., \& Fox, K.R. (2008). Physical self-perceptions and self-esteem in male basketball players with and without disability: A preliminary analysis using the physical self-perception profile. European Journal of Adapted Physical Activity, 1(1), 35-49.

Fox, K.R. (1997). The physical self: From motivation to well-being. Champaign, IL: Human Kinetics.

Fox, K.R., \& Wison, P. (2008). Self-perceptual systems and physical activity. In T. S. Horn (Ed.), Advances in sport psychology (3rd ed., pp. 49-65). Champaign, IL: Human Kinetics.

Harter, S. (2012). The construction of the self: Developmental and sociocultural foundations (2nd ed.). New York: Guilford Publications.

Marsh, H.W., Asci, F.H., \& Tomas, I.M. (2002). Multitrait-multimethod analyses of two physical self-concept instruments: A cross-cultural perspective. Journal of Sport and Exercise Psychology, 24(2), 99-119. 
Marsh, H.W., Papaioannou, A., \& Theodorakis, Y. (2006). Causal ordering of physical self-concept and exercise behavior: Reciprocal effects model and the influence of physical education teachers. Health Psychology, 25(3), 316.

Marsh, H.W., Richards, G.E., Johnson, S., Roche, L., \& Tremayne, P. (1994) Physical Self-Description Questionnaire: Psychometric properties and a miiltitrait-meltimethod analysis of relations to existing instruments. Journal of Sport and Exercise Psychology, 16(3), 270-305.

Martin, J.J. (2002). Training and performance self-efficacy, affect, and performance in wheelchair road racers. The Sport Psychologist, 16(4), 384-395.

Martin, J.J. (2008). Multidimensional self-efficacy and affect in wheelchair basketball players. Adapted Physical Activity Quarterly, 25(4), 275-288.

McAuley, E. (1993). Self-efficacy and the maintenance of exercise participation in older adults. Journal of Behavioral Medicine, 16(1), 103-113.

McAuley, E., Elavsky, S., Motl, R.W., Konopack, J.F., Hu, L., \& Marquez, D.X. (2005). Physical activity, self-efficacy, and self-esteem: Longitudinal relationships in older adults. The Journals of Gerontology Series B Psychological Sciences and Social Sciences, 60(5), 268-275.

Moore, J.B., Mitchell, N.G., Bibeau, W.S., \& Bartholomew, J.B. (2011). Effects of a 12-week resistance exercise program on physical self-perceptions in college students. Research Quarterly for Exercise and Sport, 82(2), 291-301.

Motl, R.W., McAuley, E., \& Snook, E.M. (2007). Physical activity and quality of life in multiple sclerosis: Possible roles of social support, self-efficacy, and functional limitations. Rehabilitation Psychology, 52(2), 143.

Qasim, S., Ravenscroft, J., \& Sproule, J. (2014). The effect of Karate practice on self-esteem in young adults with visual impairment: A case study. Australian Journal of Educational and Developmental Psychology, 14(spec. iss.), $167-185$

Rosenberg, M. (1965). Society and the adolescent self-image. Princeton: NJ: Princeton University Press.

Rumsey, N., \& Harcourt, D. (2004). Body image and disfigurement: issues and interventions. Body Image, 1(1), 83-97.

Sabiston, C., Whitehead, J.R., \& Eklund, R.C. (2012). Exercise and selfperception constructs. In G. Tenenbaum, R. C. Eklund \& A. Kamata (Eds.), Measurement in sport and exercise psychology (pp.227-238) Champaing, IL: Human Kinetics.

Scarpa, S. (2011). Physical self-concept and self-esteem in adolescents and young adults with and without physical disability: The role of sports participation. European Journal of Adapted Physical Activity, 4(1), 38-53.

Shapiro, D.R., \& Martin, J.J. (2010). Multidimensional Physical Self-Concep of Athletes with Physical Disabilities. Adapted Physical Activity Quarterly, 27(4), 294-307.

Sherrill, C., Hinson, M., Gench, B., Kennedy, S.O., \& Low, L. (1990). Selfconcepts of disabled youth athletes. Perceptual and Motor Skills, 70(3 suppl), 1093-1098.

Sonstroem, R.J., Harlow, L.L., \& Josephs, L. (1994). Exercise and self-esteem: Validity of model expansion and exercise associations. Journal of Sport and Exercise Psychology, 16(1), 29-42.

Sonstroem, R.J., \& Morgan, W.P. (1989). Exercise and self-esteem: rationale and model. Medicine \& Science in Sports \& Exercise, 21(3), 329-337. 